\title{
Family history and breast cancer
}

\author{
June C. Carroll MD, Ruth Heisey MD, Ellen Warner MD
}

\section{A family history can identify poten- tial carriers of $B R C A$ mutations who should be offered genetic counselling}

Look for families with multiple cases of breast cancer or at least two relatives on the same side of the family (maternal or paternal) who had breast cancer before 50 years of age, or any case of ovarian cancer, bilateral breast cancer or breast cancer in a man. ${ }^{1}$ Breast cancer before 60 years of age in women of Ashkenazi Jewish descent also suggests increased risk. ${ }^{1}$ If the criteria for genetic testing are met, ${ }^{1}$ family members who have had cancer are tested first. If a $B R C A 1$ or $B R C A 2$ mutation is found, testing can be offered to unaffected relatives. Criteria for genetic testing vary across Canada - consult your local genetics clinic.

Referral to a genetics clinic will clarify risk and management

These clinics perform a personalized risk assessment using a detailed family history of cancer. Families who meet criteria for genetic testing will receive a full discussion of its benefits, risks and limitations. People who are not at high risk, either because they do not meet the criteria for testing or because their tests were negative for a known family mutation, can be reassured. People who have a $B R C A$ mutation, or who are at high risk based on family history but have an uninformative test result, will receive management recommendations. Women with a lifetime risk of breast cancer greater than $20 \%-25 \%$ should be offered annual screening with magnetic resonance imaging (MRI) and mammography. ${ }^{5}$

\section{BRCA1 and BRCA2 mutations increase the risk of breast and ovarian cancers}

Table $1^{2-4}$ outlines the predicted cumulative risk of cancer in the general population and among male and female carriers of $B R C A$ mutations.

\begin{tabular}{|c|c|c|c|}
\hline \multirow[b]{2}{*}{$\begin{array}{l}\text { Type of cancer and } \\
\text { cumulative risk }\end{array}$} & \multicolumn{3}{|c|}{ Cumulative risk, \% } \\
\hline & $\begin{array}{c}\text { Carrier of } \\
\text { BRCA1 } \\
\text { mutation }\end{array}$ & $\begin{array}{c}\text { Carrier of } \\
B R C A 2 \\
\text { mutation }\end{array}$ & $\begin{array}{c}\text { General } \\
\text { population }\end{array}$ \\
\hline \multicolumn{4}{|l|}{ Women } \\
\hline \multicolumn{4}{|l|}{ Breast cancer } \\
\hline to age $40 \mathrm{yr}$ & 12.0 & 7.5 & 0.5 \\
\hline to age $70 \mathrm{yr}$ & 54.0 & 45.0 & 7.2 \\
\hline \multicolumn{4}{|l|}{ Ovarian cancer } \\
\hline to age $40 \mathrm{yr}$ & 3.2 & 0.7 & $<0.1$ \\
\hline to age $70 \mathrm{yr}$ & 39.0 & 16.0 & 0.7 \\
\hline \multicolumn{4}{|l|}{ Men } \\
\hline \multicolumn{4}{|l|}{ Breast cancer } \\
\hline to age $70 \mathrm{yr}$ & 1.2 & 6.8 & $<0.1$ \\
\hline
\end{tabular}

\section{Clinical interventions for carriers of a $B R C A$ mutation can save lives}

Women who have BRCA mutations may choose bilateral mastectomy (for $>90 \%$ reduction in the incidence of breast cancer) ${ }^{1,5}$ or annual screening with MRI and mammography from age 25-30 years, 5 with or without chemoprevention. ${ }^{6}$ All women who opt for a risk-reducing mastectomy should be offered immediate or delayed breast reconstruction. There is no effective screening for ovarian cancer, but bilateral salpingo-oophorectomy before menopause, after childbearing is completed, will almost eliminate the risk of ovarian cancer and will reduce the risk of breast cancer by $50 \%$. $^{\text {? }}$

For references, please see Appendix 2, available at www.cmaj.ca/lookup/suppl/doi :10.1503/cmaj.111670/-/DC1
Resources on family history and risk are available for patients and health care professionals

Appendix 1 (available at www.cmaj .ca/lookup/suppl/doi:10.1503/cmaj $.111670 /-/ \mathrm{DC} 1)$ outlines several online resources.

Competing interests: Ellen Warner has consulted for Bayer Schering Pharma; she has received grant funding from Amersham Health. No other competing interests were declared.

This article has been peer reviewed.

Affiliations: From the Department of Family and Community Medicine (Carroll, Heisey), University of Toronto; Mount Sinai Hospital (Carroll); Women's College Hospital (Heisey); Princess Margaret Hospital (Heisey); Odette Cancer Centre (Warner), Sunnybrook Health Sciences Centre; and the Department of Medicine, University of Toronto (Warner), Toronto, Ont.

Correspondence to: June C. Carroll, jcarroll @mtsinai.on.ca

CMAJ 2012. DOI:10.1503/cmaj.111670 